\title{
Suicidal Attempt by Hanging-Unusual Evolution-Case Report
}

\author{
*Cristina Otilia Laza, Mostafa Sarv, Cristian Aftenie and Dan Mihail \\ Scju "Sf Apostol Andrei" Ent/Omf Clinic, Constanta, Romania
}

Submission: July 21, 2018; Published: July 27, 2018

*Corresponding author: Cristina Otilia Laza, Scju "Sf Apostol Andrei” Ent/Omf Clinic, Constanta, Romania, Email: cristinaotilia@gmail.com

\begin{abstract}
Hanging is the most common suicide method that is used by men and women also. The mechanisms of death recognized are airway obstruction, carotid sinus compression with vagal inhibition (and reflex cardiac arrest), arterial blockage with brain ischemia, blockage of both IJV, with edema of the face, brain, tongue, larynx pharynx, fractures in cervical vertebral column with the cord injury. We present an extreme case of an 62 year-old man, who try to suicide by hanging, but he was discovered by the family still breathing. They call 911. SMURD resuscitate him and rush him to the hospital there was admitted in ICU-ENT unit. The patient was comatose, with giant edema of the head, and cyanosis, brain edema and ischemia with possible decerebration. We present this case because of a few unique particularities first the fact that he was a person with a permanent tracheostomy -5 years ago was diagnose with laryngeal carcinoma and treated with total laryngectomy and neck dissection followed by radiotherapy the extended period of time between hanging and salvage -was discovered hanging by the rope 2 days after the event still breathing -unique in cases reports all over the world. Also It example that mechanism of death can be other than respiratory asphyxia in hanging cases. Also is important to discuss the suicidal attempt in patients with cancer, and the quality of life after a mutilating surgery. even till now there are no signs of recurrence.
\end{abstract}

Keywords: Hanging-Suicidal Attempt; Totally Laryngectomy; Mechanism of Death; Permanent Tracheostomy; Mutilation

\section{Introduction}

In humans, neck seems to be a fragile part of the body, exposed to traumas the mains characteristics resulting from his anatomy are relatively small diameter, lack of bony shielding, and vital structures like airways, spinal cord, and major vessels, all representing vulnerabilities, high risk of lethal traumas [116]. Neck is joining head and trunk and limited by lower margin of corpus mandible, back margin of ramus mandible, porus acusticus externus, apex of mastoid bone and superior nuchal line on the top. Lower limits of the neck are manuvrium sterni, both clavicles, acromioclavicular joint and 7 th cervical vertebra. Between these boundaries there are important structures. Nervous structures -spinal cord, cervical plexus, brachial plexus, phrenic and vagal nerves. Locomotor system composed of seven cervical vertebrae, hyoid bone, thyroid and cricoid cartilages, muscles and fascia. Oropharynx Hypopharynx, and esophagus are gastrointestinal structures of neck. Larynx and trachea are the essential airways. Strangulation define as a disruption of normal blood and air passage in the neck -have been used by both assailants and penal systems to produce injury and death. One of the most used type of strangulation is hanging -that involves suspension by the neck. Hangings can be classified as either complete -when the whole body hangs off the ground and the entire weight of the victim is suspended at the neck. Incom plete hangings imply that some part of the body is touching the ground and that the weight of the victim is not fully supported by the neck.

Hangings may also be classified by intent as:

i. Homicidal,

ii. Suicidal,

iii. Autoerotic,

iv. Accidental (Figure 1)

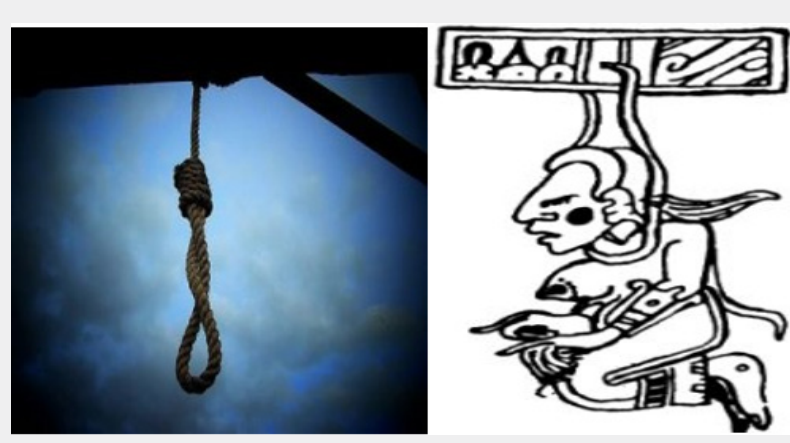

Figure 1: IXTAB-the Mayan goddess of hanging -she help dead persons by hanging to reach their haven. 
If in ancient times hanging was used as a punishment method in justice in entire world, progressively restriction of death penalties and human rights were the cause for replace this brutal method with others like lethal injection. Still hanging was used for punishment in case of spies, dictators or. Other persons as a dishonored symbol.

Accidental hanging and strangulation injuries are becoming more prevalent in urban centers in our modern world the causes are negligence, so called "choking game" autoerotic «breath play». Several populations are at risk of hanging or strangulation. Infants in postural asphyxiation, left unsupervised in their cribs usually inappropriate for a child, try to get out inserting their head between the bars and remain trapped and strangled ,Also other objects like windows cords curtains ,scarfs, cable are implicated in death of infants by hanging or strangle. Young people, adolescents with depression treated or no use hanging as a suicide method, but incidence of accidental hanging at school, at work or playing sports is large in this category of population .Also prison inmates use hanging as a suicidal good method. Other causes are autoerotic accidents, and strangulation due to «the choking game,» a practice involving voluntary near-strangulation in order to enjoy the altered mental state and physical sensations. In young adults, assault, is common usually by strangulation with bear hands, with a rope, or a belt, or a pantyhose. Strangulation injuries account for approximately $2.5 \%$ of all traumatic deaths worldwide.

Pathophysiology for strangulation injuries is controversial In a judicial hanging, the drop is at least as long as the height of the victim and the hanging is complete.

a. The mechanism of death is effectively decapitation, fracture of the upper cervical spine (typically traumatic spondylolysis of $\mathrm{C} 2$ in the classic hangman fracture), and transection of the spinal cord. Direct spinal cord injury may or may not be the cause of death in suicidal hangings.

b. In other mechanisms of strangulation injuries, manual choking, application of tool or ligature, or postural asphyxiation $(\backslash$ children whose necks are caught in an object such as a crib, a hanging towel loop, or a window cord), pathophysiologic theories include the following:

c. Compression of both IJ veins, lead to difficulties in returning of the blood to the heart with edema, hypoxia, and unconsciousness, which, in turn, produces loss of muscle tone and final arterial and airway obstruction

d. Arterial spasm due to carotid pressure, leading to low cerebral blood flow and collapse

e. Vagal collapse, pressure to the carotid sinuses and increased parasympathetic tone

f. Is the cause the for immediate cause of collapse. Many jujitsu and aikido strangles are applied to the vascular structures of the neck g. Finally asphyxia will play a part, even with tracheostomy-Several reports suicide post tracheostomy but the success of the patients was placement the ligatures above the tracheostomy, where death did not appear to be related to spinal cord injury. Strangle of the level of the trachea are capable to kill the patient because of crushing the airways and asphyxia

h. In the end death occurs from cerebral hypoxia and ischemia with neuronal death. and this is real for all types of strangulation or hanging.

In conclusion in hanging cases there are various mechanisms that lead to die it's important the type of suspension are partial and complete hanging and also the materials use for hanging most frequent are nylon rope, but can be jute, cotton rope, windows cords, belts, a metal wire or an electric cable and they use a tree branch, or a window, a pipe or a tube placed higher. Fatal period in hanging is variable, but can be few seconds to few minutes. loss of consciousness occurs very quickly, usually in a minute or less and maybe as short as 20 seconds. The brain needs a continuous supply of blood and when this is interrupted, consciousness is lost quickly. Death may take from 1 to 5 or 6 minutes. If the victim is found within 2 to 3 minutes, he would be unconscious but could wake up quickly-a couple of minutes or not. Some people die in a minute while others can take many minutes. He would probably have the typical V-shaped bruises on his neck-this is the hanging/strangle mark.

\section{Treatment}

After hanging injury those who survived enough to reach hospital are termed as "near hanging", but just a few persons can survive to this initial hanging episode. Prompt rescue to the patient of hanging injury can save their life If we want to save such a patient there are a few important steps to do for help.

\section{Prehospital Care}

When the paramedics called by the persons who discover the patient, usually the victim is already down and the cord removed and is in respiratory arrest.

\section{Stabilization of the cervical spine with a C-spine sta- bilization and airway assessment are most important}

Do not attempt endotracheal intubation in the field unless the airway is acutely compromised, ventilate the patient using a mask or a laryngeal mask, Resuscitate the patient if is in cardio-respiratory arrest. If respiratory failure exist or airway obstruction is severe prehospital intubation of the patient is indicated.

\section{Emergency Department}

a) First step is airways assessment and treatment of airway status and breathing with a possible endotracheal intubation, but remember that in complete hanging, the risk of fractures of the cervical vertebras is high direct proportional 
with the victim's weight also the spinal cord can be already damaged. In this case hyperextension of the neck is proscribed

b) Endotracheal intubation may be realized with a flexible endoscope or with a Glidescope.

c) Cricothyroidotomy is the next step indicated for any patient with airway deterioration, and difficult endotracheal intubation be unsuccessful.

d) If there are severe associated neck injuries a real tracheostomy is necessary but by an experienced neck surgeon.

e) Monitor the patient for cardiac arrhythmias.

f) Start antischock treatment with saline, glucosis, Ringer but do not forget diuretics, steroids, osmofundine to reduce edema of the face and brain

g) ENT, Neurology or ICU specialist consultation are essential in, for strangulation injuries.

h) All the patients are admitted in ICU for monitorization of vital functions depending on severity a few hours, a day or as long as is necessary.

Later a victim of hanging saved developed a lot of complications like pneumonia, hypoxic encephalopathy with pulmonary edema, brain death caused by severe hypoxia, tetraplegia in fractures of the cervical spine with spinal cord involvement this is called delayed hanging death. Saved people most of them survive between 1 and 15 days, however, survival after hanging act have been reported in the literature. The patient could return completely to normal or be left with brain damage or even remain in a coma for hours, days, weeks, months, years, or forever. It all depends upon how long the brain was deprived of blood and luck. This varies from person to person.

\section{Case Report}

We present the case of a 62 years old man , who wants to kill himself by hanging. He was discovered 2 days after the event by a member of his family ,hanging in the rope by the neck but still breathing so they call the specialized unit for emergencies -SMURD .The qualified personal resuscitate the patient, but seeing the tracheal tube they ask the family about the illness of the patient and because he breath trough the tube they clean the stoma and the tube using suction and place a mask with 02 in front of the stoma. Next, they stop the epistaxis, and otoragia, stabilized the neck with a Minerva colar and starts anti-shock treatment. Than they rush him to the hospital was admitted in ENT-ICU department. At the emergency room, we were called for consult and at ENT examination we recognize by the name an oncologic patient diagnosed and treated 5 years ago with Laryngeal carcinoma in a T3N2M0 stage but at the last control was in good shape without signs of local or regional recurrence. Perma- nent tracheal stoma was large, and clean and rigid-for these he didn't wear a tracheal tube. He was also using esophageal voice very good -because was instructed by a voice therapist at the school for voice rehabilitation. He was retired, but still work as a taxi driver. That's why I was stunned for a moment seeing my patient like this (Figure 2) [1-5].

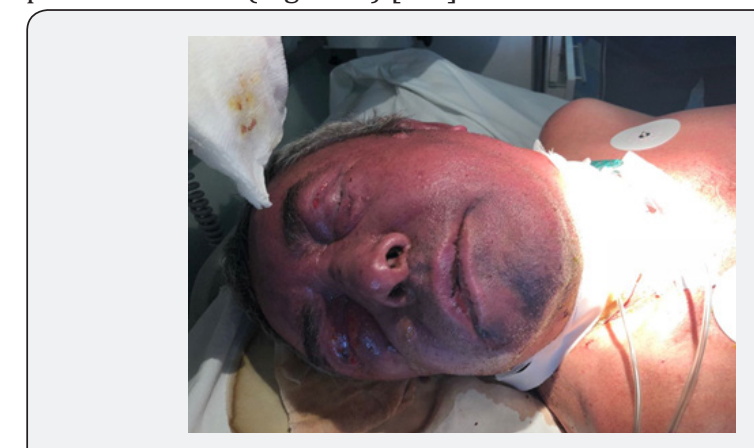

Figure 2: Patient at the emergency room, with extreme edema, cyanosis of the face, head.

At the examination patient was in coma intubated with a small tracheal tube uncuffed with mucopurulent secretions around and in the tube, also crusts. 02 was given with a mask placed over the tracheostomy the neck was with surgical incision well healed and, no lymph node but the same fibrous, wooden tissues -he is one of the patients who develop "wooden neck'-intense fibrosis of the tissues after radiotherapy. In the superior part of the neck the hanging /strangle mark was a deep circular ulceration not an ecchymosis and was visible that the knot was on the right side. This was a consequence of the compression of the tissues by the nylon rope such a long time 2 days, after an incomplete hanging - till he was saved by his son who discover his father hanging from a rope hooked from an iron bar from a door [6-10].

The superior extremity was extremely enlarged because of a giant edema of the head and face with cyanosis, edema of the eye lids, chemosis, petechial hemorrhages, right side epistaxis, otorrhagia on the right side (Figure 3 ). On the left side the edema was minor but mucopurulent rhinorrhea was important. We clean the nasal cavities, mouth and trachea by aspiration and saline, we reintubate the patient with a cuffed tracheal tube number 10 special designed to aloud connection to a ventilator. Next, we clean with betadine the deep ulceration circular around the neck (Figures $4 \& 5$ ). After clinical examination and with the patient stabilized -intubated and ventilated, we command a CT - of the head, neck and thorax -abdomen, to evaluate the real damages of the status of the brain, large vessel of the neck, cervical spine, thorax, after such a long period of strangulation -his survival was considered impossible. The results of scanning of the patient's structures are CT scan-cerebral- All the structures in the midline, edema of the brain, no hemorrhages or ischemic regions. Extreme edema of the epicranial tissues and of the face, bilateral pansinusitis with polypoidal mucosa and air -fluid aspects. The lesions were more intense on the left side CT 


\section{Global Journal of Otolaryngology}

scan of the neck -reveal normal cervical spine vertebras, normal spinal cord absence of the larynx-posts-surgery, no hyoid bone -consequence of the surgery -total laryngectomy, we perform a suprahyoid resection imposed by the tumoral extensions. Also, no lymph nodes were visible, the large vessels of the neck present, visible with the contrast iv substance, except IJV on the right size [11-15].

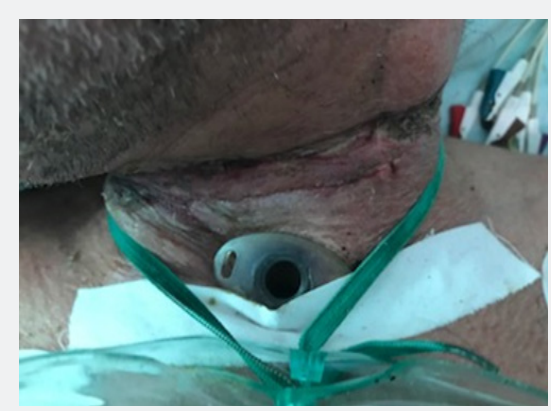

Figure 3: Total laryngectomy, tracheostomy aloud the patient to breath.

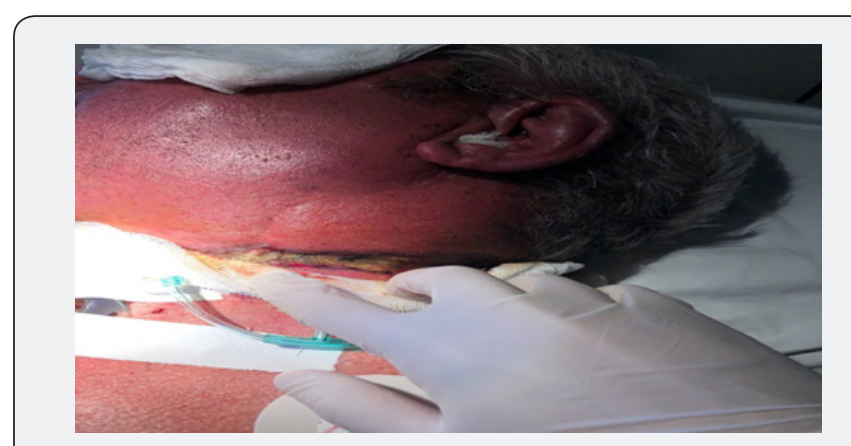

Figure 4: Hanging mark is usually an ecchymosis like a ring but in this case it's a circular deep ,necrotic ulceration like a groove , because of the long period when the rope strangle the neck -2 days.

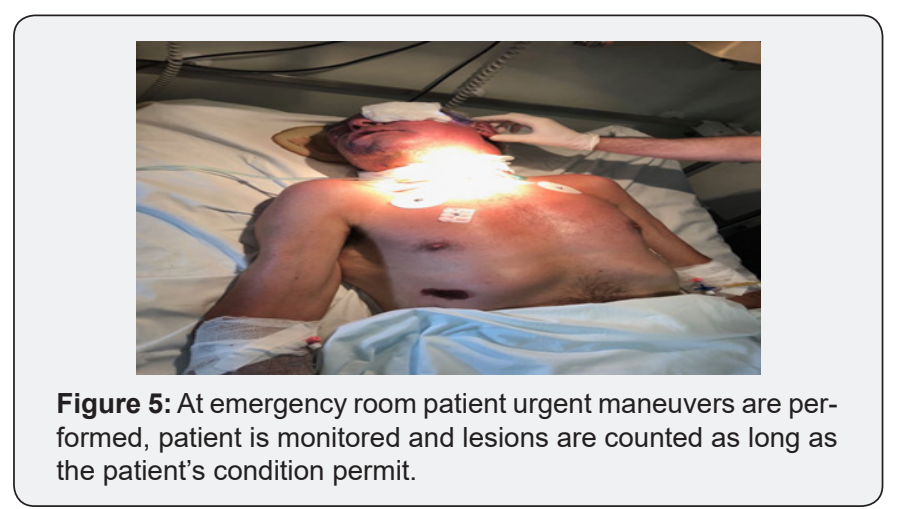

CT scan of the thorax describe tracheal tube and diffuse bilateral opacities -bilateral bronchopneumonia (Figure 6). The other consultations required were neurology -who decide that our patient is decerebrated or if he will live the brain damages are severe, but we start to reduce the edema with steroids, diuretics and osmolytes. The pneumologist confirm the diagnosis of bronchopneumonia so we choose the best antibiotics for the sinuses and for the lung. Day by day we clean the sinuses with aspirations and we insert a vasoconstrictor for decongestion and best drainage of the sinuses. Also, we clean with betadine, peroxide the contact lesion, the circular ulceration caused by the rope, we remove progressively the necrotic tissue, pulverized an antibiotic local in the wound and change the dressing (Figure 7). Also, every day we change the cannula we aspirate the endotracheal muco-purulent, very thick secretions in the first days than mucous and finally serous. If in the beginning the saturation in $\mathrm{O}_{2}$ was between $90-93 \%$ on ventilation, after day 3 he was capable to breath alone, maintaining a saturation of $99-96 \%$ with $\mathrm{O}_{2}$ inserted in the stoma (Figure 8). On the day 7 an $\mathrm{x}$-Ray of the thorax shows a serious improvement, the vital signs were stable, no fever, he react at pain and other stimuli so they transfer the patient in our department [16].

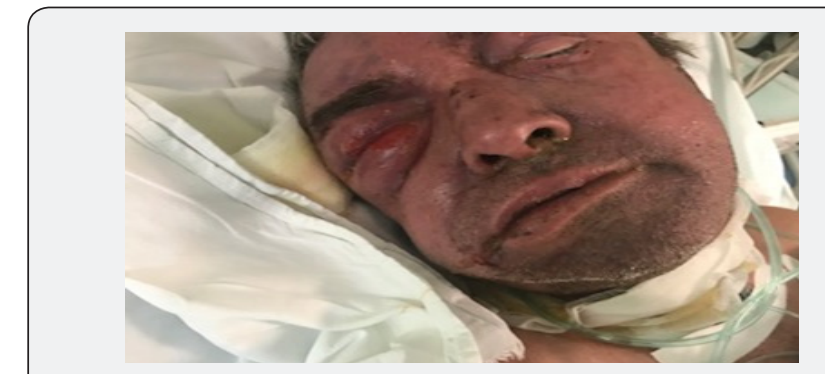

Figure 6: Edema of the face is more severe on the right side of the face ,also of the eyelids, also epistaxis and otorrhagia.

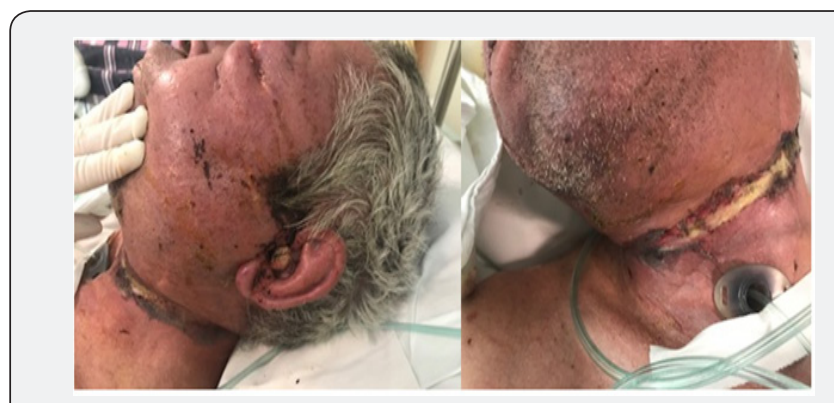

Figure 7: Hanging mark -with deep necrosis, otorrhagia, important facial edema.

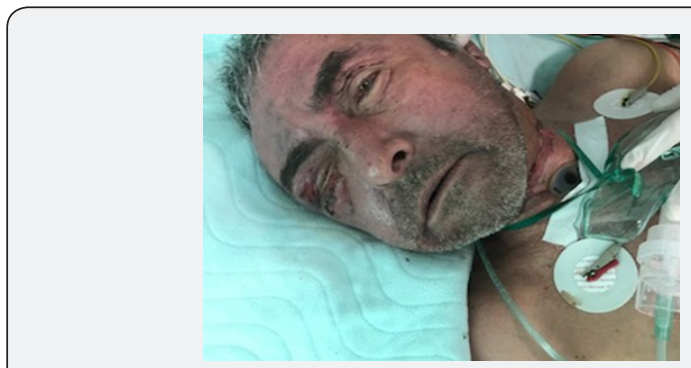

Figure 8: The patient in our department awake, opens his eyes.

We continue the treatment and we saw the patient awake, opening the left eye, capable to swallow and capable to execute commands like "open your mouth", swallow". Day by day seems to improve but than I was sceptic about a recovery after such a long period of hypoxia But no one can predict if he will be normal or with permanent brain damage or another complication will appear. Now after almost a month my patient is alive, and he 
continue the process of recovery because he can walk, he can eat but he is still confuse, he didn't remember names, events. Like permanent damages he remain with seizures, and difficulties in movement on the right hand.

\section{Discussion}

I insist to present this case because it's unique

i. $\quad$ First attempting suicide by hanging in a patient with tracheostomy is very rare

ii. Second-to survive 2 days hang by the neck so tight it's extreme-I didn't find a report of a similar case

iii. How can we explain his performance to live after such a trauma

\section{iv. Cause and relation cancer-suicide}

For a better understanding I discuss with the family and the personal from SMURD about signs of fighting, self-defense, blood was around the head of the patient. He use a nylon rope and make a knot tight after 3 loops around the neck ,the knot was placed on the left side and an iron bar from the door was used for suspension so it was an incomplete hanging by dropping .That's why the patient remain with the rope around the neck till was discovered by his son hanging from the rope ,with a blue face ,blood on the face and around the head, also urine because of involuntary emission. The stoma save him from asphyxiation so he remain still hanging with the tight knot around the neck.

Normally in such cases because of compression on the carotid sinus most patients enter in cardiovascular arrest -cardiac inhibition due to sympathetic stimulation. In our patient because of neck dissection not only that we ligate and resect in block with the lymph node metastasis the internal jugular left vein, but we remove the mass from the large vessels so for sure the sensible tissue of the sinus was destroyed, plus scars, plus radiotherapy. Another factor important is that our patient even was treated with a modest dose of radiation -50Gy develop a rare form of radio dermitis with a fibrous, wooden neck but not a severe form.

Because of ligation of the right IJV probably his body create new veins to drain that part but still incomplete in severe condition. That's why the patient develop edema more important than in the left side. Together all can explain how was possible that a hanged patient to survive 2 days till was found by the family. There is no case reported in the literature with such a long time of survival -usually maximum was 20 minutes. But this doesn't exclude a later death caused by complications like cerebral edema hypoxic encephalopathy, or pulmonary edema, bronchopneumonia, pneumonia. Pulmonary edema occurs immediately in patients following their rescue from acute airway obstruction is one of the most common complication and commonest cause of death. It is due to hydrostatic forces and increase capillary permeability (capillary membrane damage) following sudden airway obstruction. Cerebral hypoxia which triggers release of vasoactive mediators like histamines, serotonin and kinins causing pulmonary vasoconstriction, and sudden fall in intrapulmonary pressure due to abrupt release of obstruction leads to pulmonary hyperemia. Next common cause of delayed hanging death is development of hypoxic encephalopathy- brain damage if blood supply for the brain is cut off for $4-5$ minutes but it is variable.

a. Occlusion of neck arteries supplying to the brain, to which may be added failure to oxygenate the blood due to occlusion of the airway.

b. The cerebral blood flow ceases, because of stoppage of heart. Hypoxia causes necrosis of brain cells edema and swelling, ultimately causes encephalopathy. Then combined with stasis lung (congestion) and infection leads to respiratory failure.

c. Pneumonia as next cause of delayed death is caused by lung stasis, congestion and infection.

Duration of suspension, compressive force and early resuscitation are main factors important in survival of hanging the attempting suicide was a family problem, the patient was left by his wife because after 5 years of abstinence he start to drink. After two days when he try to find her at relatives, friends, he committed suicide in his house. Here are to discuss a lot of problems, because indirect is cancer related. The patient after 5 years from being diagnosed with Laryngeal carcinoma is in remission with no signs of local or regional recurrence What about quality of life, don't forget that he was force to accept a mutilating operation, who save him twice. Laryngeal carcinoma when was diagnose was in a T3N2M0 stage.In this stage the best results are obtained with first surgery-total laryngectomy with bilateral neck dissection ,functional on left side and modified with resection of IJV on the right side ,followed by radiotherapy ..There were no complications, healing was perfect and patient optimistic. 6 weeks after surgery starts the radiation protocol with two sessions of chemotherapy before to increase radio sensibility.Also the patient respect the follow-up program,also quit smoking and alcohol. Than we discuss about the voice rehabilitation and I send him to a special school to learn esophageal voice. It was a big success. After 3 years without recurrence local or regional, he came for a check up at 6 months. Also, he prefer to stay without tracheal tube because we create a large, rigid stoma. Even with a good voice rehabilitation, a lot's of them feel and are treated by other people like weird, contagious, all are scared by the hole in the neck and avoid them. This happens with strangers but also with friends and in the family. So progressive isolation, depression are very frequent plus the permanent fear that the cancer can return. Also, the relation with a partner of life especial intimate are a serious problems. Quality of life in head and neck cancer patient it is a serious and long subject and can be the cause for a suicidal attempt. 


\section{Conclusion}

Attempted suicide by hanging is a reality, some people quite famous are incapable to accept the reality of a severe diagnosis like cancer or of an incurable disease-remember Robin Williams. Head and neck cancer patients they have to fight not only with cancer but with mutilation, tracheostomy, gastrostomy-they face rejection in society but even in the family with severe depression. Our case choose hanging method to die, although he knew that he could continue to breath trough the permanent tracheostoma. This may let us think that in reality he didn't want to die. just to impress his wife. Fatal period in attempted hanging is not fixed but 48 hours period of time between hanging act and initial resuscitation is extreme. Early resuscitation and meticulous treatment of the present lesions and of possible complications may give them a second chance of life. In our case it's impossible to understand how was possible to survive 2 days with the neck strangled so tight, and how he recover after such a long period of hypoxia of the brain. Also, he succeed to pass over a severe complication like bronchopneumonia. We don't know all about mechanism of death by hanging, asphyxia for sure is not the only one but my patient and the entire family are convinced that tracheostomy save him, Doctor, your operation as much as I hate it, save me twice."

\section{References}

1. Asirdizer M, Yavuz MS, Aydin SD, Dizdar MG (2010) Suicides in Turkey between 1996 and 2005: general perspective. Am J Forensic Med Pathol 31(2): 138-145.

2. Suicide Statistics (2011) Ankara: Turkish Statistical Institute, Printing Division, Ankara.

3. Biswas H, Islam MR, Das TC (2009) Medicolegal, Legal and Social Issues in a Case of Hanging. Dinajpur Med Col J 2(1): 32-36.

4. Clément R, Redpath M, Sauvageau A (2010) Mechanism of Death in Hanging: A Historical Review of the Evolution of Pathophysiological Hypotheses. Journal of Forensic Sciences 55(5): 1268-1271.
5. Rayes M, Mittal M, Rengachary SS, Mittal S (2011) Hangman's fracture: a historical and biomechanical perspective. J Neurosurg Spine 14(2): 198-208.

6. Hellier C, Connolly R (2009) Cause of death in judicial hanging: a review and case study. Medicine, Science and the Law 49(1): 18-26.

7. Robbins KT, Clayman G, Levine PA, Medina J, Sessions R, et al. (2002) Neck dissection classification update: revisions proposed by the American Head and Neck Society and the American Academy of Otolaryngology-Head and Neck Surgery. Arch Otolaryngol Head Neck Surg 128(7): 751-758.

8. Nikolic S, Micic J, Atanasijevic T, Djokic V, Djonic D (2003) Analysis of Neck Injuries in Hanging. The American Journal of Forensic Medicine and Pathology 24(2): 179-182.

9. Tracqui A, Fonmartin K, Géraut A, Pennera D, Doray S, et al. (1998) Suicidal hanging resulting in complete decapitation: a case report. International Journal of Legal Medicine 112(1): 55-57.

10. Rothschild MA, Schneider V (1999) Decapitation as a result of suicidal hanging. Forensic Science International 106(1): 55-62.

11. Tsokos M, Türk EE, Uchigasaki S, Püschel K (2004) Pathologic features of suicidal complete decapitations. Forensic Science International 139(2): 95-102.

12. Godin A, Kremer C, Sauvageau A (2012) Fracture of the cricoid as a potential pointer to homicide. A 6-year retrospective study of neck structures fractures in hanging victims. Am J Forensic Med Pathol 33(1): 4-7.

13. Sarma K, Kola S (2010) The socio-demographic profile of hanging suicides in Ireland from 1980 to 2005. J Forensic Leg Med 17(7): 374377.

14. Davies D, Lang M, Watts R (2011) Paediatric hanging and strangulation injuries: A 10-year retrospective description of clinical factors and outcomes. Paediatr Child Health 16(10): 78-81.

15. Re L, Birkhoff JM, Sozzi M, Andrello L, Osculati AM (2015) The choking game: A deadly game. Analysis of two cases of "self-strangulation" in young boys and review of the literature. J Forensic Leg Med 30: 29-33.

16. Dunsby AM, Davison AM (2011) Causes of laryngeal cartilage and hyoid bone fractures found at postmortem. Med Sci Law 51(2): 109113.

\section{Your next submission with Juniper Publishers will reach you the below assets}

- Quality Editorial service

- Swift Peer Review

- Reprints availability

- E-prints Service

- Manuscript Podcast for convenient understanding

- Global attainment for your research

- Manuscript accessibility in different formats ( Pdf, E-pub, Full Text, Audio)

- Unceasing customer service

Track the below URL for one-step submission https://juniperpublishers.com/online-submission.php 